\title{
OPERATIONAL AND DESIGN PARAMETERS OF UNIFIED VEHICLES
}

\author{
ALEKSEY G. AMOSOV ${ }^{1}$, VLADISLAV A. GOLIKOV ${ }^{1}$, MIKHAIL V. KAPITONOV ${ }^{2}$, \\ EKATERINA V. MIKHAILOVA ${ }^{\mathbf{1}}$ \& EKATERINA YU. CHURAKOVA ${ }^{\mathbf{1}}$ \\ ${ }^{I}$ Faculty of Applied Mechanics, Moscow Aviation Institute (National Research University), Russia, \\ ${ }^{2}$ Faculty of Wheeled Vehicles, Moscow Polytechnic University, Russia
}

\begin{abstract}
The purpose of the article is to summarize and analyze the problems of design and operation of heavy trucks and semi-trailers in difficult road conditions and on terrains, subject to severe wetting. The state of knowledge of the issue, possible solutions and normative base are considered for a more detailed solution.

Operation provides the vehicle with high performance that will allow it to work in the most difficult road conditions i.e. on reconnaissance areas. However, if the main work of the unit is carried out on the roads, and it is necessary to go to the area only in the event of some unforeseen circumstances, then the traction and speed characteristics close to (or even coinciding) the characteristics of road units should be considered reasonable.

KEYWORDS: Transport Units, Design, Movement Of The Unit, Laws Of Motion, Off-Road Movement \& Operation
\end{abstract}

Received: Feb 25, 2019; Accepted: Mar 15, 2019; Published: Apr 24, 2019; Paper Id.: IJMPERDJUN201946

\section{INTRODUCTION}

At present, the tendency of weighting of goods transported by heavy-load transport and technological units continues. Under these conditions, the development of a vehicle for a particular load is very laborious, despite the unification of a number of units and parts of the units. In addition, this situation significantly complicates the research and improvement of units and systems of heavy-load and technological units, since this has to be dealt with at the developmental stage, when any design change may lead to a violation of the production time of the unit (Ankinovichet al, 2017).

At the same time, when developing according to the principle of a series of lifting capacities of the family of heavy- load transport and technological units, the vehicles of this family will ensure the transportation of all goods in a given mass range. In this case, it is easier to resolve the issue with the development of units and systems intended for use in aggregates of the family.

All over the world, the "modular" layout of a vehicle has recently become widely used. This is a set of identical elements of the wheel systems (as a rule, wheeled carts, one or several of which can be traction) using which the chassis, trailers and semi-trailers of different carrying capacities are made. Moreover, along with the connection of such modules in the longitudinal direction, a cross-connection is often used, as a result of which it is possible to transport large or large-diameter cargoes.

In the practice of operating heavy transport and technological units, sometimes there are difficulties when driving on certain sections of roads in adverse meteorological conditions. Therefore, it is necessary to again evaluate the following road parameters that determine the mobility of the vehicle: the values of rolling resistance 
and adhesion coefficients, as well as the elevation angles of the roads that may be on the route and which should be taken into account in dynamic traction calculations. This will make it possible to identify the main operational and design parameters of heavy load transport and technological units - the coefficient of adhesion weight, power and speed.

\section{ANALYSIS OF EXISTING HEAVY VEHICLES}

\subsection{Foreign Aggregates}

Among heavy duty vehicles of different countries, trailed and semi-trailed road trains are the most common: selective calculations show that each of these vehicles accounts for approximately $40 \%$ of the total number of heavy trucks (Antonov, 1978). The rest are single chassis and road trains with intermediate carts - about $10 \%$ each. It should, however, be noted that trailers and semi-trailers have a more fractional division in terms of load-carrying capacity compared to single chassis and road trains with intermediate carts.

The gross mass of the heaviest vehicles now reaches 1000-1500 tons with a lifting capacity of 800-1100 tons (Gorelov and Tropin, 1998), however, there are few such units, while vehicles with a carrying capacity of 200-300 tons are quite common. Many firms produce heavy trucks of only 1-2 lifting capacities. At that time, leading enterprises in this area, as a rule, have a whole range of units, formed either by a set of the corresponding number of axles, or by connecting the same running modules (Vinokurov et al, 1998).

According to analysis of the operating conditions of vehicles, it can be noted that all units are designed for driving on high-class roads or on special sites. This conclusion is based on the fact that all single chassis and road trains are nonwheel-drive, and they have a very small coefficient of adhesion weight. Another confirmation of good road conditions is the low frame of many vehicles (Malanin and Ayupov, 1984).

A common feature of almost all heavy-duty units today is the low power density. At the same time, there is such a fact: if before the passport speed of movement of heavy trucks did not exceed, as a rule, 3-5 $\mathrm{km} / \mathrm{h}$, then in recent years this figure has increased dramatically and now reaches 20 or even $30 \mathrm{~km} / \mathrm{h}$ (Osepchugov et al, 1956).

As a part of road-trains, heavy trucks are used as special tractors (ballast and saddle), as well as general-purpose tractors. Most of the heavy trucks are towed by the general purpose (mainly triaxial), with the possibility of unlimited movement on public roads. Special tractors for heavy-duty trucks have some features: full drive, high adaptability of the engine to variable driving conditions, "creeping" speed and some others, but the high axial load of these machines hinders their use (Lychin and Zhilekin, 2017).

Heavy trucks are quite different in size: the length of the cargo link varies from a few meters to 100-110 m, width in some cases reaches $6 \mathrm{~m}$, finally, the height of the cargo link (without load) is 0.9-3.7 m (Osepchugov, 1956).

Road trains with two-four-wheel semi-trailers sometimes have fully or partially unmanaged wheel systems of the cargo link. Generally, heavy vehicles have the ability to rotate wheels, axles, bogies or wheel travel as a whole, which indicates a large variety of control schemes used for wheeled vehicles and, as calculations show, allows most units to fit into the road with a very small turning radius $m$ and less).

The most common semitrailers are trailers with a platform above the wheels, as well as with a low-lying curved platform. There are frequent cases of designing a vehicle with a platform of variable height or with a sliding platform, which expands the operational capabilities of the unit (Chudakov, 1950; Shaar, 1938). 
Finally, it should be said that wheels (tires) in heavy vehicles use very different sizes, but more often small tires occur (the same sample calculation shows that more than $30 \%$ of vehicles have tires of $7.50 \times 15$ with a diameter of less than $1 \mathrm{~m}$ ) (Kachaturov, 1982).

Recently, a combined semi-trailer is becoming widespread - a cargo link with two multi-axle wheel moves (front and rear) and a lift-mounted hitch device, which connects to the tractor seat. In this design, the main advantages of a semitrailer with an intermediate carriage are used - the high coupling qualities of the road train - and the trailer - a large carrying capacity and good lateral stability.

Thus, it is possible to conclude that there is a large variety of overseas heavy vehicles, both in terms of execution schemes and in terms of design solutions.

In general, it can be noted that the domestic heavy vehicles on the main indicators are close to similar foreign technology. At the same time, if foreign wheeled vehicles are all designed for operation along good roads and highways, then we clearly have two directions in operation. Accordingly, in the design of the vehicle - along with road machines, designed, like foreign ones, for good roads, there is another group of wheeled units - special purpose vehicles operating on roads of mostly lower categories. A special, very small group of domestic vehicles is off-road wheeled vehicles, operated, as a rule, on explored routes on the ground (Shiryaev, 1964).

\section{ROAD AND OFF-ROAD OPERATION}

The greater the electrical power of a train, the higher its average speed, ceteris paribus. However, an excessively large engine power causes high fuel consumption and increased initial and operating costs, relatively little increasing the traction and speed characteristics of the vehicle. At the same time, the low power of the engine cannot provide the auto train with the necessary traction and speed qualities on the climbs.

There is no single indicator characterizing the performance of road trains. The most complete is the value of the power density of the train. However, this indicator does not take into account some important factors affecting the dynamic qualities and fuel economy of the road train. For example, with a successful combination of transmission and engine characteristics, it is possible to obtain optimal performance from a train with a relatively low-powered engine. It is known, firstly, that a number of foreign companies use tables made up of the previous experience of their work, and, secondly, it is well known that Faun tractors work well as part of such heavy road trains, whose specific power is only $3 \mathrm{hp} / \mathrm{t}$ (Chudakov, 1947).

The RS SEV and GOST 21398-75 have the following requirement: full-load trucks must overcome a 3\% rise with a length of at least $3 \mathrm{~km}$, while the steady speed must be at least $30 \mathrm{~km} / \mathrm{h}$ (with $f=0.02$ ). This requirement can be met at a power density of the order of 11-12 hp / t and it is mainly due to the presence of the vehicle in the general traffic flow. For super-heavy units, the provision of such power density is now simply unrealistic, and the requirement of movement in the general flow is not considered yet.

The maximum speed of the vehicle also cannot serve as the sole criterion for the choice of the power of the train. An additional condition is necessary - acceleration time (Ellis, 1975).

Practically, the problem of choosing the power density power can be solved as follows. In figure 1 shows the curves $\mathrm{N}=f(\mathrm{M})$ for vehicles of economic use (curve 1$)$ on the roads of the highest categories and special platforms $(f=$ 
0.02) and all-wheel drive vehicles and road trains on their basis (curve 2), used, in particular, for army needs in heavy road conditions $(f=0.1)$. Proportional recalculation of curves 1 and 2 for the conditions in which heavy-load vehicles are operated gives curve $3(f=0.05)$ and curve 4 (annual average $f=0.036$ ), the zone between which can serve as a guideline for selecting the specific power of super-heavy special-purpose vehicles.

The maximum vehicle speed can be determined for specific road conditions by the known $\eta$ t $\eta \mathrm{N}$ relationship (Gosstroy, 1986)

$$
\mathrm{N}=3.7 \mathrm{IV}_{\max } \frac{f+t g \alpha}{\eta_{\mathrm{T}} \eta_{N}}
$$

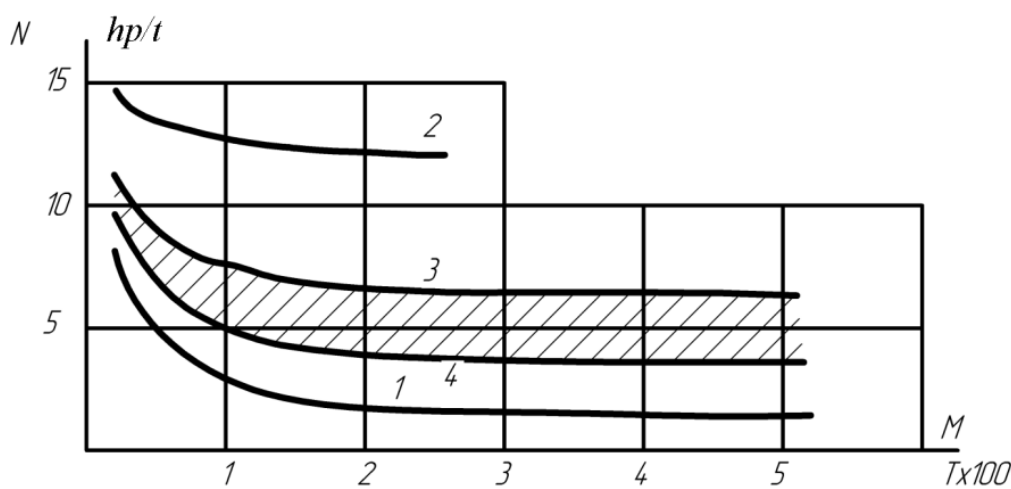

1 - Farming vehicles $(f=0.02)$

2 - All-wheel drive cars and road trains based on them $(f=0.1)$

3 - Vehicle on roads with $\mathrm{f}=0.05$

4 - Vehicle on roads with $\mathrm{f}=0.036$

\section{Figure 1: Specific Power of Heavy Vehicles}

From where

$$
\mathrm{V}_{\max }=\frac{\mathrm{N}_{\mathrm{yd}} \eta_{\mathrm{T}} \eta_{\mathrm{N}}}{3.71(\mathrm{f}+\mathrm{tg} \mathrm{a})}
$$

Where $\eta_{\mathrm{T}^{-}}$transmission efficiency; you can take $\eta_{\mathrm{T}}=0,6$ for design calculations of heavy vehicles;

$\eta_{N}-$ the coefficient of effective use of engine power; can roughly be considered $\eta_{N}=0.8$ (Bourcier, 1951)

\begin{tabular}{|c|c|c|c|c|c|c|}
\hline \multirow[t]{2}{*}{ Coefficient Assignment } & \multirow[t]{2}{*}{ Tires } & \multirow[t]{2}{*}{ Season } & \multicolumn{3}{|c|}{$\begin{array}{l}\text { Coefficient on Roads According } \\
\text { to SNiP P-D.5-72, Road Category }\end{array}$} & \multirow[t]{2}{*}{$\varphi$} \\
\hline & & & I & II, III & IV, V & \\
\hline \multirow{4}{*}{$\begin{array}{l}\text { To calculate the coefficient of } \\
\text { adhesion weight } \mathrm{K}_{\text {adh }} \text { (the road is } \\
\text { in satisfactory condition, the } \\
\text { worst combinations of } f \text { and } \varphi \text { ) }\end{array}$} & \multirow{2}{*}{ High pressure } & summer & 0.018 & 0.025 & \multirow{2}{*}{0.040} & 0.30 \\
\hline & & winter & \multicolumn{2}{|c|}{0.035} & & 0.20 \\
\hline & \multirow{2}{*}{ Low pressure } & summer & 0.020 & 0.030 & \multirow{2}{*}{0.050} & 0.35 \\
\hline & & winter & 0.030 & 0.035 & & \\
\hline \multirow{2}{*}{$\begin{array}{l}\text { For calculation of power and } \\
\text { maximum speed (summer road } \\
\text { with good condition of coverage, } \\
\text { worst readings } f \text { ) }\end{array}$} & High pressure & & 0.015 & 0.020 & 0.030 & \\
\hline & Low pressure & & 0.018 & 0.025 & 0.040 & \\
\hline
\end{tabular}

Table 1: Estimated Coefficients $f$ and $\varphi$ on the Roads in the Areas of Operation

Using data from tables 1 and 2, you can find the maximum speed on the roads in the areas of operation. These data are summarized in Table 3 
Thus, the specific power of heavy vehicles at the upper boundary of the shaded zone in Figure 1.2 (about $6.5 \mathrm{hp} /$ t) provides the unit with a maximum speed on the I-III road categories in the horizontal section - 33-56 km / h, on the climbs - more than $26 \mathrm{~km} / \mathrm{h}$; on the road of lower categories (IV-V), the maximum speed on a horizontal stretch is up to 21-28 km / h, on rises - more than 18-23 km / h. The lower limit of the shaded area in terms of power density (3.8 hp / t) provides the vehicle with significantly lower speed indicators (Morrison and Cebon, 2016).

Table 2: Maximum Estimated Vehicle Speed Depending on Operational Parameters

\begin{tabular}{|c|c|c|c|c|c|}
\hline \multirow{2}{*}{$\begin{array}{c}\text { Road Category } \\
\text { According to } \\
\text { SNiP }\end{array}$} & \multirow{2}{*}{ Tires } & \multirow{2}{*}{$\begin{array}{c}\text { Estimated } \\
\text { Coefficient } f\end{array}$} & \multirow{2}{*}{$\begin{array}{c}\text { Tangent of } \\
\text { Elevation Angle } \\
\text { of the Road tg } \alpha\end{array}$} & \multicolumn{2}{|c|}{$\mathrm{V}_{\max }, \mathrm{km} / \mathrm{h}$ with Power Density } \\
\hline & & & & $6.5 \mathrm{hp} / \mathrm{t}$ & $3.8 \mathrm{hp} / \mathrm{t}$ \\
\hline \multirow{4}{*}{$\mathrm{I}$} & \multirow{2}{*}{ High pressure } & \multirow{2}{*}{0.015} & 0 & 56 & 33 \\
\hline & & & 0.06 & 40 & 23 \\
\hline & \multirow{2}{*}{ Low pressure } & \multirow{2}{*}{0.018} & 0 & 46 & 27 \\
\hline & & & 0.06 & 35 & 20 \\
\hline \multirow{4}{*}{ II, III } & \multirow{2}{*}{ High pressure } & \multirow{2}{*}{0.020} & 0 & 42 & 25 \\
\hline & & & 0.07 & 31 & 18 \\
\hline & \multirow{2}{*}{ Low pressure } & \multirow{2}{*}{0.025} & 0 & 33 & 19 \\
\hline & & & 0.07 & 26 & 15 \\
\hline \multirow{4}{*}{ IV, V } & \multirow{2}{*}{ High pressure } & \multirow{2}{*}{0.030} & 0 & 28 & 16 \\
\hline & & & 0.07 & 23 & 13 \\
\hline & \multirow{2}{*}{ Low pressure } & \multirow{2}{*}{0.040} & 0 & 21 & 12 \\
\hline & & & 0.07 & 18 & 10 \\
\hline
\end{tabular}

The average speed of the vehicle in real conditions can be estimated by the maximum speed,

$\mathrm{V}_{\mathrm{avg}}=\mathrm{K}_{\mathrm{avg}} \mathrm{V}_{\max }^{\alpha=0}$

where $K_{\mathrm{avg}}$ - coefficient depending on the state of the road surface; for roads with a satisfactory condition of coverage (heavily worn surface) $\mathrm{K}_{\mathrm{avg}}=0,4-0,7 / 4 /$;

$\mathrm{V}_{\max }^{\alpha=0}-$ maximum vehicle speed on a horizontal road with good coverage.

Values $\mathrm{V}_{\text {avg }}$ are given in table 3, with which you can estimate the time required by the vehicle to perform the transport operation.

Table 3: Average Vehicle Speed

\begin{tabular}{|c|l|c|c|}
\hline \multirow{2}{*}{$\begin{array}{c}\text { Road Category } \\
\text { According to } \\
\text { SNiP }\end{array}$} & \multirow{2}{*}{ Tires } & \multicolumn{2}{|c|}{$\begin{array}{c}\mathbf{V}_{\text {avg, }} \mathbf{k m} / \mathbf{h} \\
\text { On the Road with a Satisfactory Condition of } \\
\text { Coverage }\left(\mathbf{K}_{\text {avg }}=\mathbf{0 . 5 5} \text { with Power Density }\right.\end{array}$} \\
\cline { 3 - 4 } & & $\mathbf{6 . 5} \mathbf{~ h p / t}$ & $\mathbf{3 . 8} \mathbf{~ h p ~ / ~ t ~}$ \\
\hline \multirow{2}{*}{ I } & High pressure & 31 & 18 \\
\cline { 2 - 4 } & Low pressure & 25 & 15 \\
\hline \multirow{2}{*}{ II, III } & High pressure & 23 & 14 \\
\cline { 2 - 4 } & Low pressure & 18 & 10 \\
\hline \multirow{2}{*}{ IV, V } & High pressure & 15 & 7 \\
\cline { 2 - 4 } & Low pressure & 11 & 9 \\
\hline
\end{tabular}

\section{OFF-ROAD OPERATION OF THE VEHICLE}

On the terrain, which is subject to strong moisture, wheeled vehicles will lose mobility due to objective reasons for vehicles. In other conditions, with a higher load bearing capacity of the soil, the following vehicle indicators mainly affect the permeability of single chassis and road trains: traction properties of the vehicle on the engine and on the clutch, 
specific tire pressure on the road (soil), the relative position of the wheels along the track, angles overhang and ground clearance, transverse and longitudinal radii of terrain. Very important for off-road work is also the characteristic of the parking brake system. Finally, the question of the evacuation of heavy-duty vehicles from jamming places is quite special (Masahiro, 2007).

As for the engine thrust, then, focusing on equipment designed for operation under similar conditions, one should strive, according to Figure 1, to a power density of about $12 \mathrm{hp} / \mathrm{t}$. Adhesion properties of the vehicle in off-road operating conditions should be maximum; as for working on soils with a small coefficient of adhesion and significant resistance to movement of the vehicle, all-wheel drive vehicles are generally not suitable.

Under these conditions, using the dependences of the maximum and average speeds (1) and (2), we find for $\mathrm{f}=0.1$ and $\mathrm{K}_{\text {avg }}=0.4$ (the lower limit of the average speed for a road with a satisfactory surface condition)

$$
\mathrm{V}_{\max }=\frac{12 \cdot 0,6 \cdot 0,8}{3,71(0,1+0)}=15,5 \mathrm{~km} / \mathrm{h}, \quad \mathrm{V}_{\mathrm{avg}}=0,4 \cdot 15,5=6,2 \mathrm{~km} / \mathrm{h} .
$$

During the operation of heavy vehicles as multi-axle single chassis, as well as road trains with 3-5 axles in one wheel course, even on roads built in accordance with SNiP, wheels are hung when moving through artificial or natural unevenness, which leads to redistribution of loads on the wheels and on the frame of the vehicle. Therefore, for off-road operation, the units seem appropriate to design with 2, in extreme cases, with a 3-wheel drive with large diameter wheels (if possible, a wide profile) (Cheng and Cebon, 2008). The preferred two-wheel axle with a track allows the wheels to move next to next. This solution will allow, firstly, to increase the bearing and geometric cross-country ability of the vehicle and, secondly, to have relatively small wheel suspension movements. In conjunction with the ground clearance of about 450-500 mm, determined by the depth of the wetted soil layer, and the overhang angles of $25-30^{\circ}$, the geometrical parameters of the terrain will be at the level of the army equipment, which will allow heavy vehicles to travel across the explored area.

Under working conditions off-road, the parking brake system must ensure reliable retention of a heavy-duty vehicle on a slope. There are no standard slopes for off-road tracks, and even more so for the terrain (Fasekas, 1955). However, it is possible to determine extremely difficult road conditions for an all-wheel drive vehicle, in which it will still maintain mobility, and the slopes under these conditions can be considered as the greatest operational conditions. We find these slopes, taking the adhesion coefficient is the same as when driving on roads $-\varphi=0.2$, and the rolling resistance coefficient $f=0.1$ and $f_{\mathrm{ml}}==0.015$ :

$\operatorname{tg} \alpha=\left(\varphi+f_{\text {世I) }}\right) K_{\text {adh }}-f=(0,2+0,015) \cdot 1-0.1=0.115$.

It should be noted that the maximum permissible (in exceptional cases) slope on roads built according to $\mathrm{SNiP}$ (and this applies only to mountainous terrain) is a slope of $12 \%(\operatorname{tg} \alpha=0.12)$, thus found off-road operational slope of 11.5 $\%(\operatorname{tg} \alpha=0.115)$ can be considered as very large.

\section{CONCLUSIONS}

Evacuation of heavy vehicles from the place of jamming with modern overall-mass indicators of the vehicle is difficult, as in the conditions of road operation (due to limited room for maneuver and some other difficulties), so when working with off-road units. Extrusion of a stuck vehicle is connected, as a rule, with the application of large dynamic loads to it and causes the presence of wide tracks with a high bearing capacity of the soil. The task of taking a load from a 
stuck or damaged vehicle is also not an easy task. There are still questions that, in conjunction with these, are undoubtedly interesting in the problem of evacuation of heavy vehicles, in general, representing the subject for independent research.

This operation gives the vehicle high performance that will allow it to work in the most difficult road conditions, i.e. on reconnaissance areas. However, if the main work of the unit is carried out on the roads, and it is necessary to go to the area only in case of some unforeseen circumstances, then the vehicle's speed and speed characteristics close to (or even coinciding) the characteristics of road units should be considered reasonable.

\section{REFERENCES}

1. Ankinovich, G.G., Gorelov, V.A., Chudakov, O.I. (2017). Evaluation of the influence of the activation of the wheels of the semi-trailer on the traction-dynamic properties of the train. Proceedings of higher educational institutions. Engineering, $1(682), B / C$.

2. Antonov, D.A. (1978).The theory of stability of the movement of multi-axle vehicles. Moscow, Mashinostroenie.

3. Bourcier, de C. (1951). Sur lastabilite de route des routieres. Journal de l des umorguosroutieres journal de le SYA, XXIV(5), $W / P$.

4. Cheng, S., Cebon, D. (2008). Improving roll stability of articulated heavy vehicles using active semitrailer steering. Vehicle System Dynamics: International Journal of Vehicle Mechanics and Mobility, 46(Suppl. 1), 373-388.

5. Chudakov, E. A. (1947). The influence of the lateral elasticity of the wheels on the movement of the car. Report Academy of Sciences of the USSR, 10, 127.

6. Chudakov, E. A. (1950). Theory of the car. Moscow, Mashgiz.

7. Fasekas, G. (1955). On the Kinematic path of semitrailers. Journal of applied mechanics, 9, W/P.

8. Fernando, E. A. S. K. (2014). Mathematical model for warp tension with various back rest settings and relationship with technological parameters. International Journal of General Engineering and Technology (IJGET), 3(2), 17-26.

9. Gorelov, V. A., Tropin, S. L. (2011). Mathematical model of curvilinear movement of a train on a non-deformable support base. Journal of automotive engineers, 5, 18-22.

10. Lychin, M.T., Zhilekin, M.M. (2017). Development of principles for increasing the maneuverability of long-axle multi-axle trucks with semi-trailers. Proceedings of higher educational institutions. Engineering, 11(692).

11. Malanin, V.V., Ayupov, V.V. (1984). Determination of critical speeds and radii of the turn of the train. Depie in NIIN automotive industry, 1005ap-84dep.

12. Masahiro, O. (2007). Adaptive Lane Keeping Controller for Four-Wheel-Steering Vehicles. 2007 IEEE International Conference on Control and Automation Guangzhou, CHINA, W/P.

13. Morrison G., Cebon D. (2016). Sideslip estimation for articulated heavy vehicles at the limits of adhesion, Vehicle System Dynamics, 54(11), 1601-1628, DOI:10.1080/00423114.2016.1223326, W/P.

14. Osepchugov, V.V. (1956). About wagging two-axle trailers. Designing, research, testing cars. Moscow, 2, 17-31.

15. Osepchugov, V.V., Frumkin, A.K., Portnova, A.A. (2015). Improving the steering grader with articulated frame. Doct. Diss. Omsk.

16. Shiryaev, A.P. (1964). Investigation of the effect of turning devices on the stability of motion and turning ability of automobile trains. Doct. Diss. Moscow Automotive Institute. Moscow, 1964. 
17. SNiP 2.05.02 - 85.(1986). Roads. Gosstroy of the USSR. Moscow, TsITPGosstroy USSR.

18. Sonawane, S. A., \& Kulkarni, M. L. (2013). Effect of WEDM Machining Parameters on Output Characteristics. International Journal of Mechanical and Production Engineering Research and Development (IJMPERD) ISSN, 2249-6890.

19. Vinokurov, V. P. et al. (1998). Automobile base units of missile complexes. Moscow, p. 139. 